\title{
Tinentaon

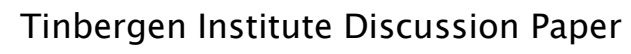 \\ Platform Intermediation in a Market for Differentiated Products
}

Andrea Galeotti

José Luis Moraga-González²

' Department of Economics, University of Essex, UK;

2 University of Groningen, CESifo, and Tinbergen Institute. 


\section{Tinbergen Institute}

The Tinbergen Institute is the institute for economic research of the Erasmus Universiteit Rotterdam, Universiteit van Amsterdam, and Vrije Universiteit Amsterdam.

Tinbergen Institute Amsterdam

Roetersstraat 31

1018 WB Amsterdam

The Netherlands

Tel.: $\quad+31(0) 205513500$

Fax: $\quad+31(0) 205513555$

Tinbergen Institute Rotterdam

Burg. Oudlaan 50

3062 PA Rotterdam

The Netherlands

Tel.: $\quad+31(0) 104088900$

Fax: $\quad+31(0) 104089031$

Most TI discussion papers can be downloaded at http:/ /www.tinbergen.nl. 


\title{
PlatForm Intermediation IN A MARKet FOR Differentiated PRODUCts*
}

\author{
Andrea Galeotti ${ }^{\dagger}$ \\ José Luis Moraga-González
}

Revised: February 2008

\begin{abstract}
We study a two-sided market where a platform attracts firms selling differentiated products and buyers interested in those products. In the unique subgame perfect equilibrium of the game, the platform fully internalizes the network externalities present in the market and firms and consumers all participate in the platform with probability one. The monopolist intermediary extracts all the economic rents generated in the market, except when firms and consumers can trade outside the platform, in which case consumers retain part of the economic rents. The market allocation is constraint efficient in the sense that the monopoly platform does not introduce distortions over and above those arising from the market power of the differentiated product sellers. An increase in the number of retailers increases the amount of variety in the platform but at the same time increases competition. As a result, the platform lowers the firm fees and raises the consumer charges. In contrast, an increase in the extent of product differentiation raises the value of the platform for the consumers but weakens competition. In this case, the platform raises both the charge to the consumers and the fee for the firms.
\end{abstract}

Keywords: Two-sided markets, network externalities, intermediation, advertising

JEL Classification: L12, L13, D42, D43

\footnotetext{
${ }^{*}$ We thank an Associate Editor and two anonymous referees for their useful comments. Mark Armstrong, Wilko Bolt, Ralf Dewenter and Vaiva Petrikaite also provided us with helpful suggestions on earlier versions. The paper has also benefited from presentations at Essex, Groningen, the SEA Conference 2004 (New Orleans), the Two-sided markets conference in Toulouse 2006, and the EARIE 2006 Meetings in Amsterdam. Moraga-González gratefully acknowledges financial support from Marie Curie Excellence Grant MEXTCT-2006-042471.

${ }^{\dagger}$ Department of Economics, University of Essex, U.K. E-mail: agaleo@essex.ac.uk

${ }^{\ddagger}$ University of Groningen, CESifo and Tinbergen Institute. E-mail: j.l.moraga.gonzalez@rug.nl
} 


\section{Introduction}

Two-sided markets are characterized by the existence of two groups of agents which derive gains from conducting transactions with each other (like for example tenants and landlords) and the existence of intermediaries that facilitate these transactions (like real state agents). Besides markets for real state, exhibitions, employment agencies, videogame platforms, internet portals, dating agencies, magazines, newspapers and journals are other examples of two-sided markets. ${ }^{1}$

An important characteristic of these environments is that market outcomes depend not only on the total level of transaction costs jointly faced by the two groups of participants (price level) but also on the particular allocation of those costs across them (price structure) (Rochet and Tirole (2006)). Several authors have studied how platform prices relate to the nature of intermediation in the market. Platform pricing in monopoly settings is examined in Armstrong (2006) and Rochet and Tirole (2003). Pricing in the presence of competing platforms is studied in various settings, including those of Anderson and Coate (2005), Armstrong (2006), Armstrong and Wright (2007), Caillaud and Jullien (2001, 2003), Gabszewicz and Wauthy (2004) and Rochet and Tirole (2003, 2006).

Most studies adopt a reduced-form approach and thus leave the activity that takes place within a platform non-modelled. The present study departs from this strategy by explicitly modelling the interaction between the two groups of participants within the platform. We consider a setting where a platform's manager tries to attract to her platform retailers selling differentiated products on the one hand and consumers interested in the firms' offerings on the other hand. We study how differentiated product sellers compete for consumers within the platform, and how the platform's manager should price its services to buyers and firms to maximize its profits. Departing from the reduced-form approach yields new insights into the nature of platform pricing and market efficiency. In particular, it allows us to examine how the price structure depends on the number of retailers and the degree of product differentiation.

There are three types of agent in the economy: a platform, $N$ firms and a unitary mass of consumers. In the benchmark model firms and consumers cannot find each other without the platform. The platform tries to lure firms and consumers to participate. Its pricing policy consists of an advertising

\footnotetext{
${ }^{1}$ See Evans (2003), Armstrong (2006) and Rochet and Tirole (2003, 2006) for an extensive set of examples.
} 
fee firms have to pay to exhibit their products and prices, and a subscription fee consumers have to pay to access product and price information. The interaction between these three types of agents is modelled via the following two-stage game. In the first stage, the platform chooses firm and consumer participation fees. In the second stage, a firm deciding to enter the platform advertises its product and the price at which it is offered. A consumer who decides to enter the platform observes the different offerings and chooses the one that maximizes his utility.

We find that continuation game equilibria with partial agent participation cannot be part of a subgame perfect equilibrium (SPE). What happens when firms and consumers do not participate surely in the platform is that the elasticity of consumer participation is positive, i.e., the fraction of subscribing consumers increases in the subscription charge. As a result, the platform has an incentive to continue to increase its consumer fee until all consumers participate. This result, which is somewhat surprising, is due to the way network externalities between the two groups of participants operate. Provided all consumers join the platform, the elasticity of firm participation is negative so the platform wishes to continue to lower its firm fee until every firm joins with probability one. In the unique SPE of the game, the platform fully internalizes the network externalities present in the market, all agents participate with probability one in the platform, and the monopolist intermediary extracts all the economic rents. The market allocation is not efficient because product sellers have market power. However, the monopolist intermediary does not introduce distortions over and above those arising from the market power of the differentiated product sellers. In an extension we allow firms and consumers to trade outside the platform. In this case, consumers capture a part of the economic rents corresponding to the option value of trading outside the platform.

As mentioned above, our framework allows for the study of the relationship between platform pricing structure and the nature of competition in the product market. Both an increase in the number of retailers and an increase in product differentiation raise the value of the platform for consumers. However, the way the platform's manager adjusts its price structure when there is variation in the number of participating firms differs from the case in which there is variation in the degree of product differentiation. Indeed, as the number of retailers increases, the products become closer substitutes from the viewpoint of the consumers and thus firms' competition becomes fiercer. As a result, the equilibrium price of the product falls, the platform lowers its firm fee and increases its consumer charge. By contrast, an increase in the degree of product differentiation relaxes firms' 
competitiveness within the platform. In this case, the equilibrium price of the product increases and the platform raises its fee for the firms as well as the price it charges to consumers.

Our paper is a contribution to the literature on intermediation. In the classical literature on intermediation, intermediaries "make the market" by choosing input and output prices to maximize their profits (see Spulber (1999) and the references therein). Some authors have analyzed how intermediated exchange can arise in competitive search markets (see e.g. Gehrig (1993) and Yavas $(1994,1996))$. This literature has experienced a recent revival in the branch of industrial organization that studies multi-sided markets. A great deal of this literature has focused on specific markets, most notably credit card markets (see Rochet and Tirole (2002), Schmalensee (2002) and Wright (2003, 2004)), the Internet (see Baye and Morgan (2001) and Caillaud and Jullien (2001, 2003)), commercial media markets (see Anderson and Coate (2005), Dukes and Gal-Or (2003a, 2003b) and Dukes (2004)), B2B marketplaces (Belleflamme and Toulemonde (2004)) and software (Hagiu, 2006). Armstrong (2006) and Rochet and Tirole (2003, 2006) present general frameworks for the study of two-sided markets; Belleflamme and Toulemonde (2007) explore the role of intragroup externalities when launching new platforms, and Nocke, Peitz and Stahl (2007) study the relation between platform ownership and platform size. ${ }^{2}$

A common feature of many papers in the two-sided market literature ${ }^{3}$ is that agents on one side of the market meet agents on the other side of the market according to an exogenously specified matching process. Even though this formulation is useful, it is somewhat incomplete for markets where one group of agents supplies rival goods to the other side of the market within the platform, like in exhibitions, fairs, real-state agents, labor agencies, etc. In these kinds of market the nature of platform pricing influences the matching process in non-trivial ways so the platform's manager has to factor this into its decision making process. Our paper models this interaction explicitly and it shows how the incentive of the platform's manager to squeeze more or less one side of the market relative to the other depends upon the specific structure of the market -number of retailers and degree of product differentiation-. In this sense, our results yield empirical predictions on the relationship between platform prices and the nature of the activity that takes place within the platform which, to the best of our knowledge, have not yet been investigated.

\footnotetext{
${ }^{2}$ See also the empirical contributions of Rysman (2004) and Kaiser and Wright (2006).

${ }^{3}$ Baye and Morgan (2001), Belleflamme and Toulemonde (2004), Dukes (2004), Nocke, Peitz and Stahl (2007) and Rochet and Tirole (2002) are notable exceptions.
} 
The papers most closely related to ours are Baye and Morgan (2001) and Dukes (2004). Baye and Morgan (2001) study how a monopoly gatekeeper on the internet can attract a share of local trade. The main differences between our paper and theirs is that we model markets for differentiated products and that in their setting centralized and decentralized trade can coexist. In an extension of our benchmark model we allow some form of decentralized trade. In contrast to Baye and Morgan (2001), we find that centralized and decentralized trade cannot coexist. Dukes (2004) studies the private and social provision of advertising in a setting where radio-stations and product sellers offer differentiated radio programmes and products to the consumers. An important difference between his paper and ours is the modelling of advertising. In his model buyers listen to the radio but dislike advertisements so there are negative firms-to-consumers network externalities; by contrast, in our setting consumers subscribe to the platform in order to receive price and product information so there exist positive firms-to-consumers network externalities.

The rest of the paper is organized as follows. Section 2 describes our benchmark model. The analysis and results are presented in Section 3. In Section 4 we allow for decentralized trade in the economy. Finally, section 5 concludes. The proofs of Claims 1 and 2 are relegated to an Appendix.

\section{A two-sided market with differentiated product sellers}

We study a two-sided market (platform) controlled by a monopolist where one group of participants are firms selling horizontally differentiated products and the other group of participants are consumers interested in those products. The monopoly platform sets its entry fees to attract both groups of participants to the platform. A firm entering the platform exhibits its product and consumers learn about its product's characteristics and the price at which the product is offered. Consumers choose among the different products on sale at the platform to maximize utility. Let $a$ denote the (fixed) fee the platform charges the firms for participation; likewise, let $s$ be the (fixed) entry fee consumers must pay to participate. ${ }^{4}$ We normalize fixed and variable cost of the platform to zero.

On the supply side of the product market there are $N \geq 2$ retailers selling a differentiated product. The sellers compete in prices. They all produce the good at constant returns to scale and their

\footnotetext{
${ }^{4}$ This pricing scheme involving lump-sum fees is reasonable in situations where monitoring transactions is quite difficult. This happens to be the case in exhibitions, fairs, yellow pages, magazines, newspapers, internet platforms, etc. See Armstrong (2006) and Rochet and Tirole (2003) for a discussion of different pricing mechanisms.
} 
identical unit production cost is normalized to zero. Retailers advertise their products and their prices in the platform. A firm $i$ may decide to enter the platform or not at all. We represent the set of pure entry-strategies as $E_{i}=\{A, N A\}$, where $A$ and $N A$ indicate the decisions to enter and exhibit the product or not to enter at all, respectively. A firm $i$ 's entry strategy is then a probability function over the set $E_{i}$. We refer to $\lambda^{i}$ as the probability with which a firm $i$ chooses to enter the platform and advertise its product, while $1-\lambda^{i}$ denotes the probability with which the firm stays out of the platform. A firm $i$ 's pricing strategy is a price $p_{i}$. A strategy for firm $i$ is thus denoted by $s_{i}=\left\{\lambda^{i}, p_{i}\right\}, i=1,2, \ldots, N$. Let $E \pi_{i}$ denote the (expected) payoff to a firm $i$.

On the demand side of the market, there is a unit mass of consumers who must subscribe to the platform to become aware of the characteristics and the prices of the products. A consumer $m$ is willing to pay $\varepsilon_{i m}>0$ for the good of firm $i$. The parameter $\varepsilon_{i m}$ represents the quality of the match between consumer $m$ and product $i$. We assume that all consumers are identical and that the matching value is the realization of a random variable uniformly distributed on $[0, \bar{\varepsilon}]$. Let $F(\varepsilon)$ and $f(\varepsilon)$ denote the uniform cumulative and probability distribution functions, respectively. A buyer demands a maximum of one unit. ${ }^{5}$ A consumer may decide to subscribe to the platform or not at all. The set of consumers' pure strategies is $R=\{S, N S\}$, where $S$ and $N S$ indicate the decisions to subscribe to and not to subscribe to the intermediary, respectively. A consumer's mixed strategy is a probability function over the set $R$. We refer to $\mu \in[0,1]$ as the probability with which a consumer enters the platform and $E u$ denotes the (expected) utility of a consumer.

The timing of moves is as follows. The platform, in the first stage of the game, chooses its entry fee for the firms and its subscription charge for the consumers to maximize its profits. In the second stage, after observing the participation fees, firms simultaneously choose whether to place ads in the platform or not and which price to charge, while consumers decide whether to enter the platform or not. Firms and consumers that do not enter the platform cannot conduct transactions. ${ }^{6}$ The market clears when transactions between firms and consumers take place. We study subgame perfect equilibria. ${ }^{7}$

\footnotetext{
${ }^{5}$ The modelling of product differentiation is in line with Perloff and Salop (1985) and Anderson and Renault (1999). Although we use the uniform distribution throughout, as shown in Caplin and Nalebuff (1991), log-concavity of $f$ implies profit functions are quasi-concave so the results obtained here are arguably more general.

${ }^{6}$ In Section 4 we relax this assumption and allow firms and consumers to trade on their own, without the platform mediation.

${ }^{7}$ Before proceeding with the analysis, we would like to clarify some technical issues. It is known that the existence of network externalities often leads to multiple equilibria. In our model there is always a SPE where no firm and
} 


\section{Equilibrium}

This section contains our main result. We first present the continuation game equilibria. For this, for any given profile of platform fees, we derive the participation rates of consumers and firms as well as the equilibrium in the product market. Then, proceeding by backwards induction, we derive the unique subgame perfect equilibrium of the game.

\subsection{Continuation game equilibria.}

We start by describing the market outcomes in the second stage of the game. Consider the behavior of a firm $i$, that takes as given the platform's entry fee $a \geq 0$, the rivals' strategies as well as consumers' behavior. Let $\mu \in(0,1]$ be the fraction of consumers subscribing to the platform. Likewise, assume a firm believes its rivals will enter the platform with probability $\lambda \in(0,1]$ and charge a price $p^{*}$. Then, the profits a firm $i$ obtains when entering the platform and charging a price $p_{i}$ (different than $p^{*}$ to allow for off-the-equilibrium pricing) are:

$$
\begin{aligned}
& E \pi_{i}\left(p_{i}, A ; s_{-i}\right)=\mu p_{i}(1-\lambda)^{N-1} \operatorname{Pr}\left[\varepsilon_{i m}-p_{i} \geq 0\right]+ \\
& \mu p_{i}\left[\sum_{k=1}^{N-1}\left(\begin{array}{c}
N-1 \\
k
\end{array}\right) \lambda^{k}(1-\lambda)^{N-1-k} \operatorname{Pr}\left[\varepsilon_{i m}-p_{i} \geq \max \left\{0, z_{k m}-p^{*}\right\}\right]\right]-a,
\end{aligned}
$$

where $s_{-i}$ denotes the strategies of firms other than $i, \operatorname{Pr}[\cdot]$ stands for probability and $z_{k m} \equiv$ $\max \left\{\varepsilon_{1 m}, \varepsilon_{2 m}, \ldots, \varepsilon_{k m}\right\}$.

The profits expression in (1) is easily understood. There are $\mu$ consumers in the platform and, if they buy from firm $i$, the firm's per-consumer profit is $p_{i}$. Since rival firms enter the platform with probability $\lambda$, a firm may find itself alone in the platform, which happens with probability $(1-\lambda)^{N-1}$. In this case the firm sells to all consumers $m$ who find the product-price combination worthwhile, i.e., if $\varepsilon_{i m} \geq p_{i}$. The firm may encounter one rival in the platform, which occurs with probability $\left(\begin{array}{c}N-1 \\ 1\end{array}\right) \lambda(1-\lambda)^{N-2}$. If, for example, firm $j$ is in the platform then firm $i$ only sell to a consumer $m$ when $\varepsilon_{i m}-p_{i} \geq \varepsilon_{j m}-p^{*}$ and $\varepsilon_{i m}-p_{i} \geq 0$. The summation captures the cases where the firm encounters $k=1,2, \ldots, N-1$ rivals in the platform. Since all consumers are ex-ante identical, we shall drop the subindex $m$ in what follows.

no consumer enters the intermediary. Similarly, one can easily choose strategies to sustain any desired outcome as a SPE. E.g., to sustain a pair $(\hat{a}, \hat{s})$ as a symmetric SPE one can propose a continuation game strategy profile where a deviation from the prescribed strategy triggers the exit of firms and consumers from the intermediary. In what follows we ignore equilibria based on these strategies because they are not robust to standard trembling-hand (perfectness) arguments. 
The probability that firm $i$ 's makes a sale to a consumer when $k$ other firms are advertising their products in the platform is:

$$
\operatorname{Pr}\left[\varepsilon_{i}-p_{i} \geq \max \left\{0, z_{k}-p^{*}\right\}\right]=\int_{p_{i}}^{\bar{\varepsilon}} F\left(\varepsilon_{i}+p^{*}-p_{i}\right)^{k} f(\varepsilon) d \varepsilon,
$$

where we have used the fact that the distribution of $z_{k}$ is $F(\varepsilon)^{k}$. Given this, we can rewrite the profits of firm $i$ as:

$$
\begin{aligned}
E \pi_{i}\left(p_{i}, A ; s_{-i}\right) & =\mu p_{i}\left[\sum_{k=1}^{N-1}\left(\begin{array}{c}
N-1 \\
k
\end{array}\right) \lambda^{k}(1-\lambda)^{N-1-k} \int_{p_{i}}^{\bar{\varepsilon}} F\left(\varepsilon_{i}+p^{*}-p_{i}\right)^{k} f(\varepsilon) d \varepsilon\right] \\
& +\mu p_{i}(1-\lambda)^{N-1}\left(1-F\left(p_{i}\right)\right)-a .
\end{aligned}
$$

Rearranging we obtain:

$$
E \pi_{i}\left(p_{i}, A ; s_{-i}\right)=\mu p_{i}\left[\int_{p_{i}}^{\bar{\varepsilon}}\left[1-\lambda+\lambda F\left(\varepsilon_{i}+p^{*}-p_{i}\right)\right]^{N-1} f\left(\varepsilon_{i}\right) d \varepsilon_{i}\right]-a .
$$

Using the expressions for $F$ and $f$, taking the first order condition with respect to price and applying symmetry $\left(p_{i}=p^{*}\right)$, yields an equation that characterizes the equilibrium price:

$$
p^{*}=\frac{\bar{\varepsilon}\left[1-\left(1-\lambda\left(1-\frac{p^{*}}{\bar{\varepsilon}}\right)\right)^{N}\right]}{\lambda N} .
$$

Claim 1. There always exists an equilibrium price $p^{*}$ which solves equation (3). Furthermore, $p^{*}$ is monotonically decreasing in $\lambda$, going from the monopoly price $\bar{\varepsilon} / 2$ down to a strictly positive number given by the solution to $p-\bar{\varepsilon}\left[1-\left(\frac{p}{\bar{\varepsilon}}\right)^{N}\right] / N=0$.

Intuitively, an increase in $\lambda$ raises the chance a firm encounters competitors in the platform so competition fosters and equilibrium price falls. Using (3) in the expression for profits (2), we find that in symmetric equilibrium a firm that enters the platform obtains profits equal to

$$
E \pi^{*}\left(p^{*}, A\right)=\mu \frac{p^{* 2}}{\bar{\varepsilon}}-a .
$$

Since equilibrium price falls in $\lambda$ (see claim 1), the profits of the firms also decrease in $\lambda$.

We now turn to the consumer side of the market. Given the strategies of the other participants in the platform, the expected utility to a joining consumer is

$$
E u^{*}(S)=-(1-\lambda)^{N} s+\sum_{k=1}^{N}\left(\begin{array}{c}
N \\
k
\end{array}\right) \lambda^{k}(1-\lambda)^{N-k}\left(1-F\left(p^{*}\right)^{k}\right)\left(E\left[z_{k} \mid z_{k} \geq p^{*}\right]-p^{*}-s\right),
$$


where $E$ denotes the expectation operator.

We now explain how equation (5) obtains. Since firms advertise in the platform with probability $\lambda$, a consumer who enters the platform may encounter no firm, which happens with probability $(1-\lambda)^{N}$; in this case, the consumer derives a net utility of $-s$. The consumer may find $k$ firms in the platform, which occurs with probability $\left(\begin{array}{c}N \\ k\end{array}\right) \lambda^{k}(1-\lambda)^{N-k}, k=1,2, \ldots, N$. In this case the consumer derives a surplus given by

$$
u_{k}=\left\{\begin{array}{cc}
z_{k}-p^{*} & \text { if } z_{k}>p^{*} \\
0 & \text { otherwise }
\end{array}\right.
$$

This surplus $u_{k}$ has distribution $G\left(u_{k}\right)=F\left(u_{k}+p^{*}\right)^{k}, 0 \leq u_{k} \leq \bar{\varepsilon}-p^{*}$. Therefore the expected surplus in this case is equal to

$$
\begin{aligned}
E\left[u_{k}\right]=\int_{0}^{\bar{\varepsilon}-p^{*}} u_{k} g\left(u_{k}\right) d u_{k} & =\left(1-F\left(p^{*}\right)^{k}\right)\left(E\left[z_{k} \mid z_{k} \geq p^{*}\right]-p^{*}\right) \\
& =\frac{k}{k+1}\left(\bar{\varepsilon}-\frac{p^{* k+1}}{\bar{\varepsilon}^{k}}\right)-p^{*}\left(1-\frac{p^{* k}}{\bar{\varepsilon}^{k}}\right)
\end{aligned}
$$

where the last equality follows from using the uniform distribution. The expression in (5) can then be written more compactly as:

$$
E u^{*}(S)=\sum_{k=1}^{N} B(k \mid \lambda, n) E\left[u_{k}\right]-s,
$$

where $B(k \mid \lambda, N)=\left(\begin{array}{c}N \\ k\end{array}\right) \lambda^{k}(1-\lambda)^{N-k}$.

Claim 2. $E u^{*}(S)$ is increasing in $\lambda$.

The economic intuition behind this fact is as follows. An increase in $\lambda$ has two positive effects on the surplus of a consumer. On the one hand, a higher $\lambda$ increases firms' competition in the platform and therefore subscribing consumers are able to buy at lower prices. On the other hand, a higher $\lambda$ increases the extent of variety in the platform, which in turn increases the expected value of the typical match between a buyer and a seller.

Equations (3), (4), and (7) allow us to characterize the equilibria in the continuation game. Depending on the magnitude of the fees charged to the two groups of participants, firms and consumers might or might not participate in the market with probability 1 . The following result summarizes the possible equilibria in the continuation game. 
Proposition 1 In the continuation game of the monopoly platform model with differentiated product sellers there may be two kinds of symmetric equilibrium.

I. An equilibrium with full consumer participation $\left(\mu^{*}=1\right)$ and either full or partial firm participation $\left(\lambda^{*} \leq 1\right)$. In this type of equilibrium firms charge a price $p^{*}$ given by the solution to (3) and enter the platform with probability $\lambda^{*} \in(0,1]$. When $\lambda^{*}<1$ it is given by the solution to

$$
\frac{p^{* 2}}{\bar{\varepsilon}}=a .
$$

II. An equilibrium with partial consumer participation $\left(\mu^{*}<1\right)$ and either full or partial firm participation $\left(\lambda^{*} \leq 1\right)$. In this case firms charge a price $p^{*}$ given by (3), $\mu^{*}$ is the solution to

$$
\mu \frac{p^{* 2}}{\bar{\varepsilon}}=a,
$$

and when $\lambda^{*}<1$ it is given by the solution to

$$
\sum_{k=1}^{N} B(k \mid \lambda, n) E\left[u_{k}\right]=s .
$$

\subsection{Subgame perfect equilibrium.}

We now move to the first stage of the game. The monopoly platform, anticipating the equilibria of the continuation game, chooses a pair of fees $(a, s)$ to maximize its profits. The profits of the intermediary are:

$$
\Pi(a, s)=\sum_{k=1}^{N}\left(\begin{array}{l}
N \\
k
\end{array}\right) \lambda^{k}(1-\lambda)^{N-k} k a+\mu s=N \lambda a+\mu s .
$$

We first show that a SPE with partial participation of the agents does not exist. Suppose that at the equilibrium fees $(a, s)$ both groups of participants mix between participating and not participating in the continuation game. Then, by part II of Proposition 1, the equilibrium fractions of consumers $\mu$ and firms $\lambda$ who enter the platform are given by the solution to equations (9) and (10).

The LHS of equation (10) describes the consumers gross expected utility, which, as claim 2 shows, is increasing in $\lambda$. Also, the LHS of equation (9) denotes the firms' gross expected profits, which are increasing in $\mu$ and decreasing in $\lambda$. Hence, if the platform increases the consumers' charge $s$, to sustain the equilibrium $\lambda$ must increase and $\mu$ must also increase. As a result, if fees $(a, s)$ are such that both firms and consumers mix between participating and not participating then the elasticity of consumer demand for participation is positive. Therefore, the platform will continue 
to increase the consumer fee till either all consumers join $\mu=1$, or all firms join $\lambda=1$.

This result is somewhat surprising and we now explain how it relates to the externalities the two groups of participants exert on one another. Along the equilibrium path, buyers are indifferent between joining the platform and staying out of the market. Ceteris paribus, an increase in the subscription charge for the buyers $s$ makes buyer participation less attractive. For consumers to join the platform, firms should advertise in the platform more often, so that consumers can expect to find (on average) a better match. On the other hand, as retailers enter the platform more often they also face stronger competition. Hence, a higher firms' participation rate would only be consistent with the expectation that consumers also join the platform more often. Such positive cross-group externalities which characterize the equilibrium under partial consumer and firm participation, immediately imply that the profits of the monopoly platform are strictly increasing in the subscription fee $s$.

We then need to investigate two cases. First, consider that the case in which $\lambda=1$ and $\mu \in(0,1)$. Part II of Proposition 1 tells us that in this case $\mu$ is given by the solution to the zero-profits condition (9). Therefore, the problem of the monopoly platform is

$$
\begin{aligned}
& \max _{a, s}\{N a+\mu s\} \\
& \text { s.t. } \mu p^{* 2}=\bar{\varepsilon} a,
\end{aligned}
$$

where $p^{*}$ solves (3) and therefore does not depend on $\mu$. The constraint of this problem tells us that, given that $\mu<1$, if the intermediary increases the participation fee for the firms, then consumers must subscribe to the intermediary with higher probability, which results in an increase in intermediary's profits. Hence, the platform will continue to increase $a$ till $\mu=1$.

Consider now the other case in which there is full consumer participation, $\mu=1$, and partial firm participation, $\lambda \in(0,1)$. In this case the problem of the monopoly platform is

$$
\begin{aligned}
& \max _{a, s}\{N \lambda(a) a+s\} \\
& \text { s.t. } E u^{*}(S) \geq 0 .
\end{aligned}
$$

Since the consumer demand for participation is inelastic, the intermediary has an incentive to continue to increase its charge $s$ till the constraint is binding, i.e. $E u^{*}(S)=0$. Using the expression 
for utility above, the problem of the intermediary is

$$
\max _{a}\left\{N \lambda a+\sum_{k=0}^{N} B(k \mid \lambda, N)\left(1-F\left(p^{*}\right)^{k}\right)\left(E\left[z_{k} \mid z_{k} \geq p^{*}\right]-p^{*}\right)\right\} .
$$

We note that

$$
\sum_{k=0}^{N} B(k \mid \lambda, N)\left(1-F\left(p^{*}\right)^{k}\right) p^{*}=p^{*}\left[1-\left(1-\lambda\left(1-\frac{p^{*}}{\bar{\varepsilon}}\right)\right)^{N}\right]=\frac{p^{* 2} \lambda N}{\bar{\varepsilon}}=N \lambda a,
$$

where we have used conditions (3) and (8). Hence, the problem of the monopoly platform can be rewritten as

$$
\max _{a}\left\{\sum_{k=0}^{N} B(k \mid \lambda, N)\left(1-F\left(p^{*}\right)^{k}\right) E\left[z_{k} \mid z_{k} \geq p^{*}\right]\right\}
$$

where $\lambda$ solves condition (8).

We now claim that intermediary's profits are monotonically decreasing in $a$. To see this, note that $\lambda$ is decreasing in $a$. Hence, if $a^{\prime}>a$ then $\lambda\left(a^{\prime}\right)<\lambda(a)$ and therefore $B(\cdot \mid \lambda(a), N)$ first order stochastically dominates $B\left(\cdot \mid \lambda\left(a^{\prime}\right), N\right)$. Since $\left(1-F\left(p^{*}\right)^{k}\right) E\left[z_{k} \mid z_{k} \geq p^{*}\right]$ is increasing in $k$, it follows that, for a fixed $p^{*}$,

$$
\sum_{k=0}^{N} B(k \mid \lambda(a), N)\left(1-F\left(p^{*}\right)^{k}\right) E\left[z_{k} \mid z_{k} \geq p^{*}\right]>\sum_{k=0}^{N} B\left(k \mid \lambda\left(a^{\prime}\right), N\right)\left(1-F\left(p^{*}\right)^{k}\right) E\left[z_{k} \mid z_{k} \geq p^{*}\right] .
$$

Moreover, if $a$ increases, the price charged by firms increases (because $\lambda$ decreases) and this decreases the profits of the intermediary, ceteris paribus. Overall, by increasing advertising fees the intermediary's profits fall. Hence, the platform will continue to lower its advertising fee $a$ up to the point where all firms participate with probability one.

Proposition 2 In the monopoly platform model with differentiated product sellers the unique outcome which can be sustained as a SPE takes the following form: The monopolist sets an entry fee for the firms equal to

$$
a^{*}=p^{* 2} / \bar{\varepsilon}
$$

and charges the consumers a fee equal to

$$
s^{*}=\frac{N}{N+1}\left(\bar{\varepsilon}-p^{*}-a\right) .
$$


Firms enter the platform with probability 1, advertise a price $p^{*}$ which is the solution to

$$
p^{*}=\frac{\bar{\varepsilon}}{N}\left(1-\left(\frac{p^{*}}{\bar{\varepsilon}}\right)^{N}\right),
$$

and obtain zero expected profits. Consumers subscribe to the intermediary with probability 1 and obtain zero expected utility. In subgame perfect equilibrium, the monopoly platform obtains a profit $\Pi=\frac{N}{N+1}\left(N a+\bar{\varepsilon}-p^{*}\right)$.

We now discuss two aspects of Proposition 2. First, we note that the equilibrium outcome is constraint efficient in the sense that the monopolist intermediary does not introduce any distortion over and above the one caused by the market power of the differentiated product sellers. The reason for this is that the monopolist can efficiently internalize the externalities between buyers and sellers by decreasing the firms' fee and increasing the consumers' charge, which maximizes agent participation and thus the welfare created within the platform. ${ }^{8}$

Second, in our framework the value a consumer derives from joining the platform is equal to the expected value of the best match he can find in the platform. Even though this value, which equals $\bar{\varepsilon} N / N+1$, is increasing in the number of retailers $N$ and in the degree of product differentiation $\bar{\varepsilon}$, the way platform's prices react to changes in these parameters differ from one another. In particular, as the number of retailers in the platform goes up, prices go down due to the competition effects so consumer gains not only because more products are available at the platform but also because products are offered at lower prices. As a result, the platform's manager lowers firm fees and raises consumer charges. Asymptotically, as the number of retailers tends to infinity, the market becomes perfectly competitive, firms price at marginal cost, and every consumer always finds her "ideal" product. In this extreme case, firms are granted free access to the platform and the bulk of the profits of the intermediary is made from charging the consumers.

In contrast, an increase in product differentiation softens firm competition within the platform so prices go up. Notice from Proposition 2 that when the product differentiation parameter increases then prices increase in such a way that the ratio $p^{*} / \bar{\varepsilon}$ is constant. Hence, inspection of the platform's pricing strategy reveals that firms' fee increases and consumers' charge also increases.

\footnotetext{
${ }^{8}$ In the models of Armstrong (2006) and Rochet and Tirole (2003), by contrast, the market outcome is not efficient because of agent heterogeneity. Here it is not efficient because of the market power of the agents in one side of the market. When $N \rightarrow \infty$, firm pricing becomes competitive and the market allocation is efficient.
} 


\section{Extensions}

In the previous section we have analyzed a market that was completely intermediated in the sense that transactions could not occur without the intermediary's mediation. In this section we relax this assumption by allowing consumers and firms to meet outside the platform and trade if they wish so. When decentralized and centralized trade can coexist, the question that arises is whether firms can price discriminate across channels or not. For convenience, we first study a model in which price discrimination is possible. This case is simpler and serves to illustrate the effect of the new outside option (decentralized trade) the players have. Then we discuss the case in which price discrimination is not possible.

\subsection{Decentralized trade and price discrimination}

Consider the same model as in Section 2 with the modification that firms and consumers have an opportunity to trade outside the platform. We model this idea in a similar way as in Baye and Morgan (2001). A consumer can subscribe to the intermediary or trade outside the platform; likewise, a firm can advertise its product in the platform or not. A firm that advertises in the platform charges a price which we denote as before, $p^{*}$. The firm charges a (different) price, denoted $p_{o}$, to the consumers who show up at the shop directly. So, we are allowing the firms to price discriminate here: a firm that advertises its product in the platform sells at a price $p^{*}$ to the subscribing consumers while it charges a price $p_{o}$ to the non-subscribing consumers. Consumers who subscribe to the intermediary see all the products available at the price $p^{*}$ and choose the one that matches them best. When they don't subscribe to the intermediary they pick one retailer at random and buy at the price $p_{o} \cdot{ }^{9}$ Finally, and for simplicity, we also assume that a consumer who enters the intermediary cannot trade outside the platform within the current trading period, even if he finds no suitable product in the platform.

Let us start with the continuation game equilibria. Let $\mu$ be the fraction of consumers subscribing to the intermediary. Let $\lambda$ be the probability a rival firm is advertising its product in the intermediary's platform. Consider the behavior of a firm $i$ that does not advertise in the intermediary. The optimal price $p_{o}$ to be charged outside the platform maximizes

$$
E \pi_{i}\left(p_{o}, N A ; s_{-i}\right)=\frac{1-\mu}{N} \operatorname{Pr}\left[\varepsilon_{i}-p_{o} \geq 0\right] p_{o},
$$

\footnotetext{
${ }^{9}$ The assumption that a consumer only samples one firm picks the idea that each consumer has a local firm to buy from (cf. Baye and Morgan, 2001), or that searching outside the platform is very costly.
} 
and therefore $p_{o}=\bar{\varepsilon} / 2$ (the monopoly price). The expected profits to a firm $i$ when it does not subscribe to the intermediary is $E \pi^{*}\left(p_{o}, N A\right)=\frac{\bar{\varepsilon}(1-\mu)}{4 N}$.

Consider now a firm $i$ that advertises its product in the intermediary, at a price $p_{i}\left(\neq p^{*}\right)$. The expected profits of this firm are

$$
\begin{aligned}
E \pi_{i}\left(p_{i}, A ; s_{-i}\right) & =\mu p_{i}\left[\sum_{k=1}^{N-1}\left(\begin{array}{c}
N-1 \\
k
\end{array}\right) \lambda^{k}(1-\lambda)^{N-1-k} \operatorname{Pr}\left[\varepsilon_{i}-p_{i} \geq \max \left\{0, z_{k}-p^{*}\right\}\right]+\right. \\
& +\mu p_{i}(1-\lambda)^{N-1} \operatorname{Pr}\left[\varepsilon_{i}-p_{i} \geq 0\right]+E \pi_{i}\left(p_{o}, N A ; s_{-i}\right)-a .
\end{aligned}
$$

This expression is equivalent to the expression (1) in Section 3, with the exception that now we have a new term, namely $E \pi_{i}\left(p_{o}, N A ; s_{-i}\right)$. This new term appears because a firm that advertises in the intermediary also receives a share of the consumers who do not subscribe and buy directly from their local firms. Since firms price discriminate, this new term does not depend on $p_{i}$ and therefore the equilibrium price $p^{*}$ within the platform is the same as in (3), which is decreasing in $\lambda$ (see claim 1). From the analysis above, it is clear that the expected profits of a firm that advertises its product in the intermediary's platform can then be written as $E \pi^{*}\left(p^{*}, A\right)=\frac{\mu p^{* 2}}{\bar{\varepsilon}}+E \pi^{*}\left(p_{o}, N A\right)-a$, and it is readily seen that, as in the benchmark model, this expected payoff is decreasing in $\lambda$.

We now look at the behavior of consumers. The expected utility of a consumer who does not enter the intermediary is simply $E u^{*}(N S)=\operatorname{Pr}\left[\varepsilon-p_{o} \geq 0\right] E\left[\varepsilon-p_{o} \mid \varepsilon \geq p_{o}\right]=\bar{\varepsilon} / 8$. Consider now the expected utility of a consumer who subscribes to the intermediary. Notice that such a consumer encounters himself exactly in the same position as in the previous analysis. Therefore, his utility is $E u^{*}(S)=\sum_{k=0}^{N} B(k \mid \lambda, N) E\left[u_{k}\right]-s$ and recall that claim 2 shows that $E u^{*}(S)$ increases in $\lambda$.

We now turn to the intermediary's problem, which has profits $\Pi=N \lambda a+\mu s$. Here we can follow the steps developed in the benchmark model to show that in the subgame perfect equilibrium the intermediary will set the fees so that both firms and consumers fully participate. Suppose not and consider that both types of agents mix between participating and not participating. Then, since it must be the case that $E \pi^{*}\left(p^{*}, A\right)=E \pi^{*}\left(p_{o}, N A\right)$ and $E u^{*}(S)=E u^{*}(N S)$, we have $a=\mu p^{* 2} / \bar{\varepsilon}$ and $s=\sum_{k=0}^{N} B(k \mid \lambda, N) E\left[u_{k}\right]-\bar{\varepsilon} / 8$. Note that these equations are the same as in Proposition 1 except in that now the consumer fee $s$ is lowered by $\bar{\varepsilon} / 8$ to compensate buyers for the utility they can obtain using their outside option. Then, as in the benchmark model, the monopolist intermediary has an incentive to continue to increase the consumer charge $s$ so that both firm and consumer participation rates increase. Therefore, Proposition 2 also holds here, with the only 
modification that the consumer fee $s^{*}=\frac{N}{N+1}\left(\bar{\varepsilon}-p^{*}-a\right)-\bar{\varepsilon} / 8$ so that consumers appropriate part of the economic surplus, in particular $E u^{*}(S)=\bar{\varepsilon} / 8$. The profits of the monopoly platform are then $\Pi=\frac{N}{N+1}\left(N a+\bar{\varepsilon}-p^{*}\right)-\bar{\varepsilon} / 8$, lower than before by the amount left for consumers. The equilibrium is also constraint efficient.

\subsection{Decentralized trade in the absence of price discrimination}

We now consider the same model as above but assume that firms cannot price discriminate. That is, we assume that a firm $i$ that advertises its product at a price $p_{i}$ in the intermediary's platform also charges this price to the consumers who do not subscribe to the intermediary and happen to visit firm $i$ to conduct a transaction.

We start again with the continuation game equilibria. As before let $\lambda$ and $\mu$ be the participation rates of firms and consumers. Consider the behavior of firms. The first remark is that the optimal price of a firm that does not subscribe to the intermediary is $p_{o}=\bar{\varepsilon} / 2$, obtaining an expected profit equal to $E \pi^{*}\left(p_{o}, N A\right)=\bar{\varepsilon}(1-\mu) / 4 N$. Note that this profit decreases as consumers' subscribe more frequently with the intermediary.

Suppose now that a firm enters the intermediary and charges a price $p_{i}$, while all other firms in the intermediary charge $p^{*}$. The expected profits of firm $i$ are:

$$
\begin{aligned}
E \pi_{i}\left(p_{i}, A ; s_{-i}\right) & =\mu p_{i}\left[\sum_{k=1}^{N-1}\left(\begin{array}{c}
N-1 \\
k
\end{array}\right) \lambda^{k}(1-\lambda)^{N-1-k} \operatorname{Pr}\left[\varepsilon_{i}-p_{i} \geq \max \left\{0, z_{k}-p^{*}\right\}\right]\right]+ \\
& +\mu p_{i} \operatorname{Pr}\left(\varepsilon_{i} \geq p_{i}\right)(1-\lambda)^{N-1}+\frac{1-\mu}{N} \operatorname{Pr}\left(\varepsilon_{i} \geq p_{i}\right) p_{i}-a .
\end{aligned}
$$

Proceeding as in Section 3, we can simplify this expression to:

$$
E \pi_{i}\left(p_{i}, A ; s_{-i}\right)=\mu p_{i}\left[\int_{p_{i}}^{\bar{\varepsilon}}\left[1-\lambda+\lambda F\left(\varepsilon_{i}+p^{*}-p_{i}\right)\right]^{N-1} f\left(\varepsilon_{i}\right) d \varepsilon_{i}\right]+\frac{1-\mu}{N}\left(1-F\left(p_{i}\right)\right) p_{i}-a .
$$

Taking the first order condition with respect to $p_{i}$, using the uniform distribution and applying symmetry, $p_{i}=p^{*}$, we obtain that $p^{*}$ is the solution to

$$
p^{*}=\frac{\bar{\varepsilon}}{\lambda[N \mu+2(1-\mu)]}\left[\mu\left(1-\left(1-\lambda\left(1-\frac{p^{*}}{\bar{\varepsilon}}\right)\right)^{N}\right)+\lambda(1-\mu)\right] .
$$

Similarly to the model in section 2 , an increase in $\lambda$ fosters competition between firms within the platform and price decreases. Note that what is new in this equation compared to the simpler cases discussed before (equation (3)) is that now $p^{*}$ depends explicitly on $\mu$. In fact, $p^{*}$ is decreasing in 
the consumers' participation rate $\mu$. When $\mu \rightarrow 0$, firms only sell locally and charge the monopoly price. As $\mu$ increases the incentives to undercut the rival firms go up and the price decreases. When $\mu \rightarrow 1$, equation (12) is equivalent to equation (3). As we will see later, this dependency of the price $p^{*}$ on $\mu$ makes things difficult because it is no longer straightforward to see that when the monopolist intermediary increases the consumer fee $s$ then both $\lambda$ and $\mu$ increase. In this case, the expected profits to a firm entering the intermediary can be written as:

$$
E \pi^{*}\left(p^{*}, A\right)=\frac{\mu p^{* 2}}{\bar{\varepsilon}}+\frac{(1-\mu) p^{*}}{N}-\frac{(1-\mu) p^{* 2}}{N \bar{\varepsilon}}-a .
$$

We now study the behavior of consumers. Consider a consumer who does not subscribe with the intermediary. This consumer picks a firm, visits this firm and decides whether to buy there or not. The chosen firm may be advertising its product at the intermediary's platform (probability $\lambda$ ) or not. Therefore, the expected utility of a consumer who does not enter the intermediary is:

$$
E u^{*}(N S)=\frac{\lambda\left(\bar{\varepsilon}-p^{*}\right)^{2}}{2 \bar{\varepsilon}}+\frac{\bar{\varepsilon}(1-\lambda)}{8},
$$

which increases in $\lambda$ due to the increase in competition in the platform.

Consider now a consumer who subscribes to the intermediary. As usual, we can write out his expected utility as $E u^{*}(S)=\sum_{k=0}^{N} B(k \mid \lambda, N) E\left[u_{k}\right]-s$, with $E\left[u_{k}\right]$ defined as in (6). Armed with these equations, it is straightforward to extend Proposition 1 describing the continuation game equilibria to this situation where firms and consumers can trade on their own and firms cannot price discriminate.

More interesting is the first stage of the game, where the intermediary chooses subscription and advertising fees. Here we also argue that an equilibrium must have all consumers and firms participating surely. However, to support this claim we rely on numerical computations. By contradiction, suppose that $\mu \in(0,1)$ and $\lambda \in(0,1)$ in equilibrium so neither firms nor consumers participate with probability one. Then, as in the benchmark case, it must be the case that $a=E \pi^{*}\left(p^{*}, A\right)-E \pi^{*}\left(p_{o}, N A\right)$, while $s=E u^{*}(S)-E u^{*}(N S)$. The profit of the intermediary is then:

$$
\Pi=N \lambda a+\mu s=N \lambda\left[E \pi^{*}\left(p^{*}, A\right)-E \pi^{*}\left(p_{o}, N A\right)\right]+\mu\left[E u^{*}(S)-E u^{*}(N S)\right] .
$$

Suppose the monopolist intermediary increases its consumer fee $s$. To sustain the equilibrium, the difference between the expected utility of a subscriber and the expected utility of a non-subscriber 
has to go up, therefore $\lambda$ must increase. Indeed, an increase in $\lambda$ increases the utility of both subscribers and non-subscribers, but it increases the utility of the former more than that of the latter. The reason is that a subscriber benefits not only from the price decrease driven by the increase in competition within the platform but also from an increase in the expected quality of the match since now there are more products in the platform. The complication that arises is that as $\lambda$ goes up and the price goes down, firms are no longer indifferent between participating and not participating. In fact, the benefits from firm participation go down relative to non-participation. As a result, to restore equilibrium, $\mu$ must go up thereby increasing the gains from participating and lowering the gains from non-participating. An increase in $\mu$ however feeds back into prices (see expression (12)) again and therefore it is difficult to characterize the adjustment process in this case analytically.

\begin{tabular}{cccccccc}
\hline$a$ & $s$ & $p^{*}$ & $\lambda$ & $\mu$ & $E \pi^{*}\left(p^{*}, A\right)$ & $E u^{*}(S)$ & $E \Pi$ \\
\hline 0.010 & 0.010 & 0.497 & 0.596 & 0.0471 & 0.119 & 0.126 & 0.0124 \\
0.010 & 0.050 & 0.495 & 0.803 & 0.0502 & 0.118 & 0.127 & 0.0186 \\
0.010 & 0.070 & 0.494 & 0.913 & 0.0521 & 0.118 & 0.128 & 0.0219 \\
0.010 & 0.085 & 0.493 & 1.000 & 0.0537 & 0.118 & 0.128 & 0.0245 \\
0.050 & 0.085 & 0.471 & 0.967 & 0.2712 & 0.091 & 0.139 & 0.1197 \\
0.100 & 0.085 & 0.450 & 0.936 & 0.5472 & 0.056 & 0.150 & 0.2337 \\
0.150 & 0.085 & 0.434 & 0.913 & 0.8256 & 0.022 & 0.157 & 0.3440 \\
0.150 & 0.100 & 0.424 & 0.987 & 0.8601 & 0.017 & 0.165 & 0.3822 \\
0.170 & 0.100 & 0.418 & 0.978 & 0.9770 & 0.003 & 0.168 & 0.4302 \\
0.171 & 0.104 & 0.414 & 1.000 & 1.0000 & 0.000 & 0.172 & 0.4477 \\
\hline
\end{tabular}

Table 1: Model with centralized and decentralized trade, no price discrimination.

To shed further light on this we resort to numerical simulations of the model. Let us set $N=2$ and $\bar{\varepsilon}=1$. In Table 1 we report the equilibrium price, the participation rates of consumers and firms as well as the profits of the different agents, including intermediary's profits, for different values of consumer and subscription fees. Notice that keeping $a$ fixed, an increase in $s$ lowers equilibrium price and increases both consumer and firm participation. As a result, the intermediary will continue to increase $s$ till either $\lambda=1$ or $\mu=1$. When $\lambda=1$, the Table shows how an increase in the firms fee increases consumers participation, lowers the price and reduces firm participation. Profits of the intermediary increase anyway because consumer demand for participation is more elastic than firm demand for participation. Since an increase in $a$ decreases firm participation, this relaxes the $\lambda=1$ constraint and then the intermediaty can increase again the consumer fee. And so on and so forth till the intermediary extracts all the rents in the market except the amount it has to leave for 
the consumers to compensate them for their outside option. In the SPE of this example we have: $\left[a=3-2 \sqrt{2} ; s=\frac{8 \sqrt{2}}{3}-\frac{11}{3} ; p=\sqrt{2}-1 ; \lambda=1 ; \mu=1 ; E \pi^{*}=0 ; E u^{*}=3-2 \sqrt{2} ; E \Pi=\frac{7-4 \sqrt{2}}{3}\right]$.

\section{Conclusions}

This paper has examined a two-sided market where a platform attracts retailers selling horizontally differentiated products and buyers interested in acquiring one of those products. Firms which enter the platform announce their products and their prices. Consumers who participate in the platform receive product and price information and choose the product offering them the highest utility. The explicit modelling of intra-platform interaction has been the focus of the paper.

In the unique SPE outcome of the game, the platform fully internalizes the network externalities present in the market and the market allocation is constraint efficient. That is, the monopoly platform does not introduce distortions over and above those arising from the market power of the differentiated product sellers. When the platform is the only means for buyers and firms to get in contact, the monopolist intermediary extracts all the economic rents generated in the market. If firms and consumers can trade outside the platform, then consumers capture a part of the rents corresponding to the option value of trading outside the platform. An increase in the number of retailers increases the extent of variety in the platform but at the same time increases competition. Anticipating that the equilibrium price of the goods will fall, the platform lowers the fees paid by the firms and raises the fees paid by the consumers. An increase in the extent of product differentiation raises the value of the platform for the consumers and weakens competition. Overall, the platform raises the participation fee charged to the consumers as well as the price firms must pay to enter the platform. These are implications on the relation between platform fees and the nature of the activity that takes place within the platform are testable and, to the best of our knowledge, have not yet been investigated.

An interesting issue is how platform mediated markets compare to standard markets for differentiated products. Our benchmark model shows that the two kinds of market are similar in that they generate the same welfare levels. However, the allocation of rents differs from market to market. While the monopolist intermediary extracts all the rents in the single platform mediated market, rents are distributed across consumers and firms in a standard market. When firms and consumers 
can trade on their own, then the distribution of rents in the platform mediated market is less skewed with consumers obtaining part of the economic rents.

\section{Appendix}

Proof of Claim 1. We first prove existence. Notice that the LHS of (3) increases monotonically in $p^{*}$, and takes values on $[0, \bar{\varepsilon} / 2]$. The RHS of $(3)$ is monotonically decreasing in $p^{*}$, going from a value equal to $\bar{\varepsilon}\left[1-(1-\lambda)^{N}\right] / \lambda N$ to $\bar{\varepsilon}\left[1-(1-\lambda / 2)^{N}\right] / \lambda N$, the latter being strictly positive. It is easy to check that $\bar{\varepsilon} / 2>\bar{\varepsilon}\left[1-(1-\lambda / 2)^{N}\right] / \lambda N$ for all $\lambda$ and $N .{ }^{10}$ This concludes the first part of Claim 1. The second part of Claim 1 follows from the fact that the RHS of (3) is decreasing in $\lambda$. When $\lambda \rightarrow 0$, the RHS of (3) goes to $\bar{\varepsilon}-p$ so $p^{*}=\bar{\varepsilon} / 2$. The derivative of the RHS of (3) with respect to $\lambda$ is:

$$
\frac{\bar{\varepsilon}\left[N y(1-y)^{N-1}+(1-y)^{N}-1\right]}{\lambda^{2} N^{2}},
$$

where we are using the notation $y \equiv \lambda\left(1-p^{*} / \bar{\varepsilon}\right)$, with $y \leq 1$. The sign of this derivative is equal to the sign of $(1-y)^{N}+N y(1-y)^{N-1}-1$. Therefore we need to show that $1>(1-y)^{N}+N y(1-y)^{N-1}$ for all $y$ and $N$. Since $(1-y)^{N}+N y(1-y)^{N-1}$ is decreasing in $N$, we can safely set $N=2$. Then we have $1>(1-y)^{2}+2 y(1-y)=1-y^{2}$, which is always true. Finally, note that $\lambda \rightarrow 1$, the RHS of (3) converges to $\bar{\varepsilon}\left[1-\left(\frac{p}{\bar{\varepsilon}}\right)^{N}\right] / N$.

Proof of Claim 2. Using the convention that $E\left[u_{k=0}\right]=0$, we can rewrite the expected utility of a subscribing consumer as follows:

$$
E u(S)=\sum_{k=0}^{N} B(k \mid \lambda, N) E\left[u_{k}\right]-s .
$$

We note that the derivative of $E\left[u_{k}\right]$ with respect to $p$ equals to $-\left(\bar{\varepsilon}^{k}-p^{* k}\right) / \bar{\varepsilon}^{k}$, which is strictly negative for all $k>0$. Also note that for given $p$ then $E\left[u_{k+1}\right]>E\left[u_{k}\right]$ for all $k>0$. Indeed, if $k$ increases then $1-F(p)^{k}$ increases and $E\left[z_{k} \mid z_{k} \geq p\right]$ also increases because the expected maximum value increases with the number of draws.

Finally, note that $B(\cdot \mid \lambda, N)$ is a binomial distribution and it is well known that if $\lambda^{\prime}>\lambda$ then $B\left(\cdot \mid \lambda^{\prime}, N\right)$ first order stochastically dominates $B(\cdot \mid \lambda, N)$. Hence, since $E\left[u_{k}\right]$ is strictly increasing in $k$, it follows that an increase in $\lambda$ raises the expected utility of a consumer who participates, ceteris paribus, i.e., if $\lambda^{\prime}>\lambda$ then

$$
\sum_{k=0}^{N} B\left(k \mid \lambda^{\prime}, N\right) E\left[u_{k}\right]>\sum_{k=0}^{N} B(k \mid \lambda, N) E\left[u_{k}\right] .
$$

Combining these observations, the result follows.

\footnotetext{
${ }^{10}$ In fact, one needs to check that $1-(1-\lambda / 2)^{N}-\lambda N / 2<0$ for all $\lambda$ and $N$, which is easy to prove.
} 


\section{References}

[1] Anderson, S. and S. Coate (2005), "Market provision of public goods," Review of Economic Studies, 72-4, 947972.

[2] Anderson, S. and R. Renault (1999), "Pricing, Product Diversity, and Search Costs: a Bertrand-Chamberlin-Diamond Model" Rand Journal of Economics, 30-4, 719-35.

[3] Armstrong, M. (2006), "Competition in two-sided markets," Rand Journal of Economics, 37-3, $668-91$.

[4] Armstrong, M. and J. Wright (2007), "Two-Sided Markets, Competitive Bottlenecks and Exclusive Contracts," Economic Theory 32, 353-380.

[5] Baye, M. R. and J. Morgan (2001), "Information Gatekeepers on the Internet and the Competitiveness of Homogeneous Product Markets," American Economic Review 91, 454-474.

[6] Belleflamme, P. and E. Toulemonde (2004), "B2B Marketplaces: Emergence and Entry," CORE Discussion Paper \# 2004/78, Belgium.

[7] Belleflamme, P. and E. Toulemonde (2007), "Negative intra-group externalities in two-sided markets," International Economic Review, forthcoming.

[8] Caillaud, B. and B. Jullien (2001): "Competing cybermediaries," European Economic Review 45, 797-808.

[9] Caillaud, B. and B. Jullien (2003): "Chicken and Egg: competition among intermediation service providers," Rand Journal of Economics 34-2, 309-328.

[10] Caplin, A. and B. Nalebuff (1991): "Aggregation and Imperfect Competition: On the Existence of Equilibrium," Econometrica 59, 25-59.

[11] Dukes, A. (2004): "The advertising market in a product oligopoly," Journal of Industrial Economics, 52-3, 32748.

[12] Dukes, A. and E. Gal-Or (2003a): "Negotiations and Exclusivity Contracts for Advertising," Marketing Science, 22-2, 222-45.

[13] Dukes, A. and E. Gal-Or (2003b): "Minimum Differentiation in Commercial Media Markets," Journal of Economics and Management Strategy, 12-3, 291-325.

[14] Evans, D. S. (2003): "The Antitrust Economics of Two-Sided Markets," Yale Journal on Regulation 20, 325382 .

[15] Gabszewicz, J. J. and X. Wauthy (2004), "Two-sided markets and price competition with multi-homing," mimeograph.

[16] Gehrig, T. (1993), "Intermediation in Search Markets," Journal of Economics and Management Strategy 2-1, 97-120.

[17] Hagiu, A. (2006), "Pricing and Commitment by Two-Sided Platforms," RAND Journal of Economics, forthcoming. 
[18] Kaiser, U. and J. Wright (2006), "Price Structure in Two-Sided Markets: Evidence from the Magazine Industry," International Journal of Industrial Organization, 24, 1-28.

[19] Nocke, V., M. Peitz and K. Stahl (2007), "Platform Ownership," Journal of the European Economic Association 5(6), 1130-1160.

[20] Perloff, J. and S. Salop (1985): "Equilibrium with Product Differentiation," Review of Economic Studies 52, 107-20.

[21] Rochet, J-C. and Tirole, J. (2002): "Cooperation among Competitors: Some Economics of Payment Card Associations," RAND Journal of Economics 33(4), 549570.

[22] Rochet, J-C. and J. Tirole (2003): "Platform Competition in Two-Sided Markets," Journal of the European Economic Association 1-4, 990-1029.

[23] Rochet, J.-C., and J. Tirole (2006): “Two-Sided Markets: A Progress Report," RAND Journal of Economics 37(3), 645-67.

[24] Rysman, M. (2004): "Competition Between Networks: A Study of the Market for Yellow Pages," Review of Economic Studies 71, 483-512.

[25] Schmalensee, R. (2002): "Payment Systems and Interchange Fees," Journal of Industrial Economics 50, 103122.

[26] Spulber, D. (1999): Market Microstructure: Intermediaries and the Theory of the Firm, Cambridge University Press.

[27] Wright, J. (2003): "Optimal Card Payment Systems," European Economic Review 47, 587612.

[28] Wright, J. (2004): "Determinants of Optimal Interchange Fees in Payment Systems," Journal of Industrial Economics 52, 126.

[29] Yavas, A. (1994), "Middlemen in Bilateral Search Markets," Journal of Labor Economics 12-3, 406-429.

[30] Yavas, A. (1996), "Search and Trading in Intermediated Markets," Journal of Economics and Management Strategy 5-2, 195-216. 